\title{
"Real-Feel" Inflation: Quantitative Estimation of Inflation Perceptions
}

\author{
MICHAEL J. ASHTON*
}

Inflation expectations are believed to influence actual inflation and therefore policymaker actions. However, methods usually employed to evaluate inflation expectations are insufficient. Survey methods either record economists' forecasts of the official Consumer Price Index (CPI) (which isn't what policymakers need to know) or consumers' attempts to calculate their own inflation experience. Consumers have little chance to perform the calculations needed to accurately compute inflation. I propose functional forms to substitute for the heuristics consumers actually use to form inflation perceptions. I also propose adjustments to reconcile official price measurements with consumers' perceptions. These adjustments are corrections for cognitive biases related to loss aversion and mental accounting.

Business Economics (2012) 47, 14-26.

doi: $10.1057 /$ be. 2011.35

Keywords: inflation perceptions, inflation expectations, inflation

$\mathrm{M}$ odern monetary policy considers inflation expectations a metric of signal importance in the formulation of monetary policy. While the Taylor Rule [Taylor 1993] provides a well-known heuristic for monetary policymakers that relies on actual, not expected inflation, policy discussions rely heavily on the question of whether inflation expectations are, and will continue to be, "contained." (See, for example, selected statements of the Federal Reserve Open Market Committee (FOMC) [Board of Governors 2006, 2008, and 2010].) Current Federal Reserve Chairman Ben Bernanke [2007] himself described the importance and significance of inflation expectations in a speech by saying "Undoubtedly, the state of inflation expectations greatly influences actual inflation and thus the central bank's ability to achieve price stability" [Bernanke 2007].

In that speech, Bernanke highlights three important questions that remain to be addressed about inflation expectations:

(1) How should the central bank best monitor the public's inflation expectations?

(2) How do changes in various measures of inflation expectations feed through to actual pricing behavior?

(3) What factors affect the level of inflation expectations and the degree to which they are anchored?

According to Bernanke, the staff at the Federal Reserve struggle with even the first of these questions, although this has not deterred them from tackling the second and third questions.

Frederic Mishkin [2007] described recent changes in the persistence of inflation, the tradeoff between inflation and unemployment, and the responsiveness of inflation to other shocks as a function of well-grounded inflation expectations. To proxy inflation expectations he used the Livingston Survey of the Federal Reserve Bank of Philadelphia and the measure used in the Federal Reserve's FRB/US macroeconometric model of the United States, which itself consists of the Hoey survey ${ }^{1}$ and the Survey of Professional

\footnotetext{
${ }^{1}$ Richard B. Hoey in "Decision Makers Poll" conducted occasional surveys of inflation expectations. The number of respondents varied between 175 and 500 and included chief investment officers, corporate financial officers, bond and
}

\footnotetext{
*Michael Ashton is Managing Principal at Enduring Investments LLC, a boutique consulting and investment management company that offers focused inflation-market expertise. Prior to founding Enduring Investments, Ashton worked as a trader, strategist, and salesman for several sell-side financial institutions, including Deutsche Bank, Bankers Trust, Barclays Capital, and J.P. Morgan. Since 2003 he has played an integral role in developing the U.S. inflation derivatives markets and is widely viewed as an expert on inflation products and inflation trading. Ashton has written extensively about the use of inflation-indexed products for hedging real exposures. He runs the Inflation-Indexed Investing Association. He received a B.A. in Economics from Trinity University in 1990 and was awarded his Chartered Financial Analyst charter in 2001.
} 
Forecasters (SPF). He also referred to the Michigan Survey of Consumer Attitudes and Behavior (Michigan survey). Levin, Natalucci, and Piger [2004] also examined the response of survey measures of the inflation expectations of professional forecasters to near-term changes in actual inflation rates, begging the question of whether the expectations of forecasters, much less a survey of such expectations, are valuable measures themselves.

Mankiw, Reis, and Wolfers [2003] compared survey measures of inflation, including the aforementioned Livingston survey, the SPF, and the Michigan survey. They illustrated that both consumers and economists tend to be broadly correct about near-term future inflation, on average, but that economists tend to have tightly grouped estimates, while consumers have very dispersed views; in the year to December 2003 (their Chart 2), economist estimates generally fell between $1 \frac{1}{2}$ and 3 percent while the interquartile range of consumer expectations lay between 0 and 5 percent.

We should be careful not to dismiss the wider range of consumer expectations as representing a lack of forecasting sophistication. The wider range partly represents the fact that the economists are responding to a question about a well-defined data series - for example, the Consumer Price Index (CPI) for the Livingston survey and the GDP deflator for the SPF - while consumers are expressing their views about "the expected change in prices," which will in fact be different for each respondent. It ought also be observed that the tight grouping of economists, especially in the context of the crosscurrents of 2002-2003, suggests herding. ${ }^{2}$ This is one reason that relying on economist expectations of inflation to help inform policy may be dangerous.

Many authors, such as Gürkaynak, Sack, and Swanson [2005], have used the spread between the yield on nominal bonds and the yield on inflation-indexed bonds (such as Treasury Inflation-Protected Securities) as a market-based proxy for inflation expectations. This is a conceptually

stock portfolio managers, industry analysts, and economists. The survey began in 1978, was discontinued in March 1991, resumed in March 1993, and ended in August 1993 [Darin and Hetzel 1995, p. 33].

${ }^{2}$ Spencer and Huston [1993] presented econometric evidence that suggests economic forecasters do in fact use the previous inflation forecasts of others as one input into their own forecasts. sound method for tracking short-term responses of inflation expectations to changes in policy and nonpolicy variables, since the participants in those markets face pecuniary consequences if their inflation forecasts prove incorrect, although Ashton [2008] demonstrated that inflation swaps are a theoretically purer measure of inflation expectations, due to the presence of different financing conditions for inflation-indexed bonds and nominal bonds. This paper deals, however, with consumer inflation expectations, which are distinct from longer-term investor inflation expectations as embodied in the market for inflationindexed financial products.

In setting monetary policy, the FOMC refers to all of these measures in forming its view of what is the current state of "inflation expectations." But the fundamental problems identified by Bernanke remain.

Policymakers rely on economists to forecast inflation; relying on economists' estimates to also represent the state of inflation expectations seems to be putting a different saddle on the same horse and expecting to win the race twice.

Clearly, the FOMC would like to sample the perceptions of the people who are involved in pricesetting and wage-setting behavior. ${ }^{3}$ But consumer surveys are not ideal instruments for at least two reasons. First, as Mankiw, Reis, and Wolfers [2003] point out, taking the "median" expectation obscures a lot of information, and it isn't exactly clear what role the variation in expectations should play. Second, and more importantly, surveys of inflation don't work well because consumers do not discern inflation properly. Perceptions of inflation are muddied by a myriad of practical problems and behavioral biases that tend to impair a consumer's accurate assessment of price changes. For example:

(1) Quality change and substitution adjustments may not be recognized viscerally by consumers, although they are a necessary part of a cost-of-living index. It might also be the case that people notice downward quality adjustments ("my insurance coverage is shrinking") more than upward quality adjustments.

\footnotetext{
${ }^{3}$ In 1998, Canetti and others [1998] conducted a survey of 200 corporate price setters to find what factors are important to them in setting prices. While the study was not meant to provide an ongoing survey of expectations, some of their insights may be useful to consider in designing a better inflation-expectations gauge.
} 
(2) Consumers seem to have an asymmetric perception of inflation as a whole, as well, so that they tend to notice goods whose prices are inflating faster than the overall market basket, but to notice less the goods whose prices are not inflating as fast. This sense is enhanced by classic attribution bias: higher prices are inflation, lower prices are "good shopping."

(3) Items whose prices are volatile tend to draw more attention, and give more opportunities for these asymmetries to compound, so they tend to factor more heavily into our sensation of inflation.

(4) People have a tendency to notice price changes of small, frequently purchased items more than they notice large, infrequently purchased items even though the latter can be a bigger part of the consumption basket. Gasoline is hugely important in the mind of the consumer, even though it's not a huge part of the basket, because it is purchased frequently and its price is volatile, which means attribution bias acts constantly. ${ }^{4}$

(5) Consumers do not viscerally record imputed costs, such as owners'-equivalent rent as distinct from what they see as their costs (principal plus interest, taxes, and insurance). Even though the former is better for a CPI, the latter (which the pre-1983 method attempted to measure) probably affects perception more directly.

(6) People often perceive increases in income taxes as inflation.

Respondents who reply to questions about what they perceive inflation to be with an answer that is somewhat near the current rate of inflation are probably basing that response on their recollection of what inflation rate has actually been reported, rather than on their own consumption. It would be a daunting mental task indeed for a consumer to

\footnotetext{
${ }^{4}$ Ranyard and others [2008] tied several of these phenomena to Tversky and Kahneman's [1974] "availability" heuristic. According to Ranyard and others, "For judgements of inflation, four aspects may affect the availability of price changes: recency of purchase, frequency of purchase, size of price change, and direction of change. Price changes of more recently and more frequently purchased items may be more activated in memory, while larger price changes as well as losses (price increases) may be more salient, all of which would increase the availability of instances of price changes." The reader will soon see how the volatility and direction of price changes can be incorporated into a quantitative model of these biases.
}

catalog all of the year's purchases and to calculate the differences from the same basket from the year before. Clearly, this is not what a survey is meant to do. But it is almost as challenging for a consumer to distinguish 1 percent inflation from 2 percent inflation - that fine of a gradation in perception would be extremely unusual to find.

However, if we can model the behavioral biases then we might identify not only changes in inflation perceptions but also better understand the drivers of those changes in any particular episode. The monetary policy prescription might vary if, for example, elevated perceptions of inflation were driven because of an increase in taxes than because of an increase in the volatility of price changes in the consumption basket. $^{5}$

In this paper, I will describe methodologies to quantify, and thus to correct for, each of these perceptual biases.

\section{Correcting For Misperceived Quality and Substitution Adjustments}

A complaint that noneconomists frequently raise about the CPI is that the practice of adjusting price changes for changes in the quality of the surveyed item - in particular when the method used is hedonic adjustment-doesn't mesh with the real-life experience of inflation. A consumer might complain, "I paid $\$ 150$ for a digital camera three years ago; I just paid $\$ 200$ for a new one - there is surely no deflation in digital photography!" The fact that the new digital camera has 14.1 megapixels of resolution while the old one had 5.1 megapixels is often considered significant by the consumer, but it doesn't get mentally accounted for as a price decrease, even though the consumer is getting much more for the money.

Another gripe concerns the adjustments made to correct for substitution bias. Consumers will tend to change their consumption patterns as relative prices change, even if the absolute level of prices does not change. For example, if a consumer who consumes 50 percent chicken and 50 percent

${ }^{5} \mathrm{~A}$ better understanding of the drivers of inflation expectations may also be useful in solving other economic conundrums. As one example, Akerloff and Shiller [2009] have proposed that worker resistance to nominal wage decreases may not be due just to money illusion but also to a sense that nominal decreases are unfair in some sense. But if consumers perceive some inflation even when the measurement of CPI indicates that there is none, we must also consider that they perceive not only a nominal, but a real wage cut even if the wage cut equals the drop in prices. 
beef sees the price of beef fall 10 percent while the price of chicken rises 10 percent, he is likely to consume less chicken and more beef even though the price index consisting of equally weighted chicken and beef has not changed. ${ }^{6}$ This would be an example of an "upper-level" substitution of items that are significantly different. A more subtle, and less controversial, adjustment is made for "lower-level" substitution of very similar items, such as two different brands of orange juice. ${ }^{7}$

Because the CPI is intended to track the cost of a static standard of living, ${ }^{8}$ real-life consumers who tend to drift gradually to higher standards of living will experience price changes associated with quality improvements and opportunistic substitution, as well as those due to inflation as we understand it. All three types of price increase will tend to be recorded mentally as inflation, even though from the standpoint of the index two of them are not. ${ }^{9}$

\section{Adjusting for substitution}

Our goal here, however, is not to improve on the CPI but to converge on the consumer's perception of inflation. It is conceptually fairly easy to deduct the adjustments made for substitution and hedonics. Johnson, Reed, and Stewart [2006]

${ }^{6} \mathrm{An}$ important point is that consumers will buy more of the item whose price relative to other goods has declined (beef in this case) even if the consumer is compensated for that change. Suppose a consumer pays $\$ 10$ per week for soda, \$5 each for Coke and Pepsi (which he considers interchangeable). Now suppose the price of Pepsi doubles, but the American Society for the Promotion of Cola Products sends the consumer $\$ 5$. With the additional $\$ 5$ he could continue to buy equal amounts of Coke and Pepsi, but will he? Of course not; the consumer will spend his $\$ 10$ all on the cheaper brand and keep the extra $\$ 5$, or buy more total cola by spending the entire $\$ 15$ - but all on the cheaper brand. The consumer's utility dollar is now much higher with one (formerly interchangeable) brand.

${ }^{7}$ For an excellent explanation of lower-level substitution and why the effect is small and not particularly controversial, see the section on Substitution in Greenlees and McClelland [2008].

${ }^{8}$ The Bureau of Labor Statistics on its website points out that this is not precisely true because a true cost-of-living index would consider other factors that affect quality-of-life, such as public goods like safety or other concerns, such as water quality [U.S. Bureau of Labor Statistics 2010], but in the context of our problem it is.

${ }^{9}$ Some academic work has suggested that the quality adjustments may in fact over-adjust, perhaps giving some ammunition to the people who complain about these adjustments. See for example Gordon [2004] and Gordon and VanGoethem [2005]. demonstrate how to use other BLS indices to estimate the effects of lower- and upper-level substitution. To estimate the lower-level substitution effect, the authors compared the regular CPI-which includes a geometric-means adjustment - to the CPI-U-XL, an experimental index that used the pre-1999 method for computing lower-level substitution effects. ${ }^{10}$ To estimate the upper-level substitution effect, the authors compared the regular CPI to the chained CPI (C-CPI-U). The BLS began producing the C-CPI-U in 2002; it uses actual consumer behavior, rather than a model of it, to determine expenditure weights. Therefore, the difference between the CPI$\mathrm{U}-\mathrm{XL}$ and the C-CPI-U represents a reasonable estimate of the total of the substitution effects. ${ }^{11}$ For our purposes we can ignore the upper-level substitution effect, because the "official" CPI (CPI-U) does not incorporate the inflationlowering adjustment made in the C-CPI-U.

The CPI-U-XL is not readily available, but it can be obtained on request from the BLS. For the year ended September 2010, the difference between the CPI-U-XL and the CPI-U was 0.247 percent. The effect has been reasonably stable, ranging between 0.2 and 0.4 percent over the last decade or so. Johnson, Reed, and Stewart's [2006] estimate for the 1999-2004 period was 0.28 percent, and Greenlees and McClelland [2008] noted that unpublished results for the longer period from December 1998 to December 2007 resulted in a 0.27 percent effect. I will use that estimate as a constant, in the absence of a convenient way to access the CPI-U-XL.

\section{Adjusting for quality change}

Adjusting for the misperception of quality adjustments is more difficult, partly because this one concept affects many different parts of the CPI in different ways and because different adjustments are made depending on the type of quality change. Johnson, Reed, and Stewart [2006] state, "the net effect of hedonics from 1999 onward... on the All

\footnotetext{
${ }^{10}$ Technically, a modified Laspeyres or "Lowe" index.

${ }^{11}$ From December 1999 to December 2004, Johnson, Reed, and Stewart [2006] estimate that the total of the two substitution effects amounted to approximately 0.68 percent, although some 0.1 percent of this was due to a "functional form" effect. The authors note, however, that this was due to an "anomalously high 0.80 percent effect in 2000 " and observe that from 2001 to 2004 the aggregate effect was a modest 0.3 percent.
} 
Items index is estimated to be less than 1-hundredth of 1 percent per year, specifically +0.005 percent." This result, however, obtains from the fact that hedonic adjustment lowers the CPI for a number of categories whose weights total to around 0.7 percent of the index, but increases the CPI somewhat for Rent, Owners' Equivalent Rent (OER), and Apparel, in addition to several smaller categories. Rent, OER, and Apparel have a combined weight of around 31.5 percent of the CPI. So, the large downward adjustments to the lightweight categories are finely balanced by very small upward adjustments to the heavyweight categories.

It seems reasonable to suppose that consumers would object to thinking of the quality improvements in computers as deflation, while not being particularly opposed to the idea that their homes tend to deteriorate over time. As a coarse adjustment, I would suggest simply removing the quality adjustments that tend to depress the index. ${ }^{12}$ However, as a practical matter, the unadjusted CPI for the various categories is not available outside the BLS. Moreover, as discussed above, the effect of the quality adjustments on the overall index is quite small. Johnson, Reed, and Stewart [2006] estimate the aggregate impact of quality adjustment as around +0.005 percent. This implies that all of the categories where quality adjustments tend to lower CPI must sum to around -0.095 percent, so as a fair approximation I will use an adjustment for quality, $\mathrm{ADJ}_{\mathrm{Qual}}=+0.1$ percent.

Thus, the corrections for misperceived quality and substitution would be:

$$
\begin{aligned}
& \text { Adj }_{\text {Subs }}=\left[\left(C P I_{U-X L}\right)-\left(C P I_{U}\right)\right] \approx 0.27 \%, \\
& A d j_{\text {Qual }}=\sum_{i} \text { weight }_{i} * M A X, \\
& {\left[0 \% \text { CategoryCPI } I_{\text {unadj }}-\text { Category } C P I_{a d j}\right] \approx 0.1 \%}
\end{aligned}
$$

Note that, because I am subtracting the adjusted inflation rate for the category from the unadjusted rate, quality adjustments that tend to depress measured inflation rates will be positive in the

\footnotetext{
${ }^{12}$ Having a similar effect, but seeming a bit less biased, would be to eliminate only the hedonic adjustments that exceed a certain threshold. Deducting only those adjustments that exceeded 0.50 percent (in either direction) in a category's inflation rate would tend to remove the large negative adjustments on small-weight categories while retaining the small positive adjustments on high-weight categories, resulting in a higher perceived inflation. While this sounds less biased, it is no less arbitrary in the choice of a hurdle.
}

MAX operator - we are extracting the adjustment to add back to the rate, but only for adjustments that pull down the rate. Given present BLS methodologies, the main effect here is to add back the OER age bias adjustment, which is the single most significant quality adjustment in that direction (by a wide margin).

\section{Correcting for Asymmetric Perception (Selective Memory) of Price Changes}

A far more important effect than the mechanical adjustments that have been made to the index is the difference between the cold precision of the BLS's calculation and the hot imprecision of our perception of price changes. Daniel Kahneman and Amos Tversky demonstrated [1979] that humans (as opposed to Homo economicus) exhibit a tendency toward loss aversion; that is, a gain of a certain size is less valuable to the economic actor than is a loss of the same size.

In the context of the perception of inflation, this tendency manifests in the greater attention a consumer pays to price increases - which are economic losses to a consumer-than to price decreases. This tendency is compounded by attribution bias, in which the consumer perceives price gains as inflation and price declines as "good shopping." David Leonhardt [2008] gets the visceral sense right: "You hate that ground chuck now costs $\$ 2.83$ a pound, but you didn't notice that oranges are 31 percent cheaper than they were a year ago." He also perceptively observes, in a related but distinct problem (the confusion of nominal and real values), that

There is also something particular to inflation that aggravates loss aversion. Price increases are obvious. But price declines are often hidden. The cost of an item stays about the same for years, while everything else gets more expensive and nominal incomes rise.

This is known as reference dependence, another behavioral phenomenon first discussed (and demonstrated) by Tversky and Kahneman [1991], who introduced a functional form for the simple case of constant loss aversion as

$$
R_{i}\left(x_{i}\right)=\left\{\begin{array}{l}
u_{i}\left(x_{i}\right)-u_{i}\left(r_{i}\right) \quad \text { if } x_{i} \geqslant r_{i} \\
{\left[u_{i}\left(x_{i}\right)-u_{i}\left(r_{i}\right)\right] / \lambda_{i} \quad \text { if } x_{i}<r_{i}}
\end{array}\right.
$$

Here $R$ is called a "reference function" expressing the perceived gain or loss in utility $\left(u_{i}\left(x_{i}\right)\right.$ is a utility function describing the total utility experienced 
when $x$ units of good $i$ are possessed/consumed) in a movement from the reference amount $r_{i}$ to the amount $x_{i}$. You can see that for increases in the good, the simple difference in the utility function describes the net change in utility, whereas for decreases, the change in utility is scaled by $\lambda_{i}$. If $\lambda_{i}=1$, there is no loss aversion. Tversky and Kahneman imply that this coefficient of loss aversion should be between 0 and 1 .

This is a good form for our correcting for asymmetric perception of price changes. Instead of utility functions, we will substitute inflation rates (with a "loss" occurring when inflation goes up, so the inequalities are reversed) ${ }^{13}$ For each good $i$ in the consumption basket, the perceived price change compared with the actual price change looks like Figure 1 if $\lambda=0.6$.

Let us assume that the tendency to downplay disinflation or deflation is consistent across goods, and further assume that the "reference level" is the general degree of inflation. ${ }^{14}$ If $w_{i}$ is the weight in the basket of good $i, C P I_{i}$ is the inflation rate of good $i$, and $C P I_{U}$ is the headline inflation rate, then the aggregate adjustment we need to make to the reported CPI is given by formula (3).

$$
\begin{aligned}
& \operatorname{Adj}_{\text {SelMem }_{\text {Mem }}} \\
& \quad=\sum_{i} w_{i}\left\{\begin{array}{l}
C P I_{i}-C P I_{U} \text { if } C P I_{i}<C P I_{U}, \\
{\left[C P I_{i}-C P I_{U}\right] / \lambda \text { if } C P I_{i} \geqslant C P I_{U} .}
\end{array}\right.
\end{aligned}
$$

If $\lambda=1$, or if all goods inflate at a rate equal to the headline rate, this adjustment will be equal to zero; in all other cases (assuming $\lambda$ is bounded by $[0,1])$ this will be a positive adjustment, tending to increase the perceived rate of inflation over the coldly rational measurement thereof.

This measure is clearly related to the dispersion of the inflation rates. As I just noted, if all rates of inflation for the various goods and services in the

\footnotetext{
${ }^{13}$ Essentially, I am assuming that utility varies negatively with quality-adjusted real price change. This seems fairly reasonable.

${ }^{14}$ There is a case to be made that the correct frame may be personal income rather than the general level of price increases. Fischer [1986] argued that because the salience of a price increase is related to how well the individual can meet it, the "decrease in economic well-being" is tied to the incidence of inflation relative to income rather than the level of inflation itself. Since incomes and inflation generally rise at similar rates, I suspect this is likely to be a fairly small effect on aggregate measures of perceived inflation, but it does raise the question of whether the volatility of personal incomes relative to the volatility of inflation might be an additional factor to consider in future research.
}

Figure 1. Selective Deflation Memory

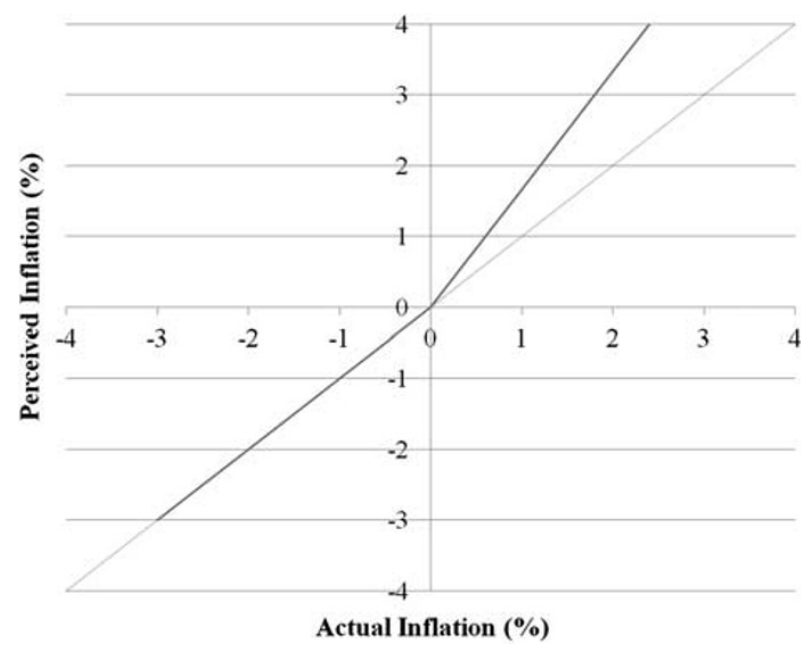

Figure 2. Adjse/Mem vs. inter-item Std Dev

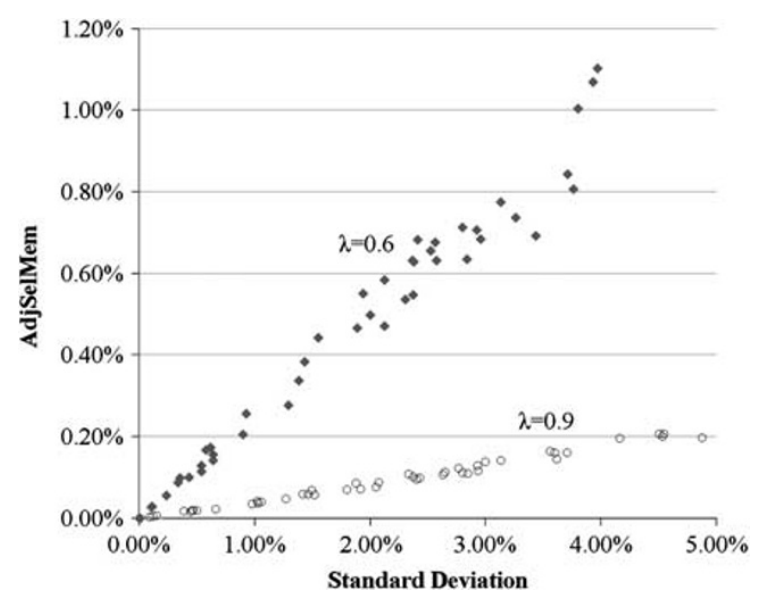

consumption basket are the same, the adjustment will be zero. As the degree of dispersion rises, the sense of inflation will also increase for any given $\lambda$. Figure 2 illustrates this effect. I generated "inflation rates" for five equally weighted hypothetical "goods" and combined them into an aggregate index. I then computed the standard deviation of the five rates, and figured the adjustment implied by equation (3). I ran multiple trials with various randomization for each of two $\lambda s$, and the effect is reasonable and expected. The size of the adjustment is positively related to the standard deviation of the sample, and inversely related to the $\lambda$.

In practice, the dispersion of actual inflation rates is much higher than a 5 percent standard 
Figure 3. Adjse/Mem, 2000-2010

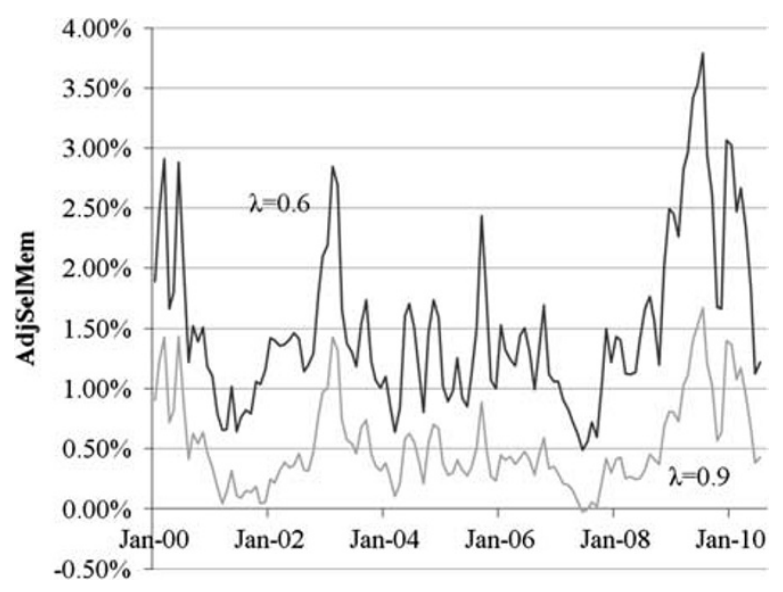

deviation. Applying formula (3) to the actual time series of CPI item strata produces the time series for this adjustment that is shown in Figure 3.

\section{Correcting for the Perception of Volatility as Inflation}

The prior correction is based on a static observation of the dispersion of inflation rates among the various groups of goods and services in the consumption basket, which gives rise to an error due to selective memory of price increases compared with decreases (relative to a reference point). Consider what happens over time, however, as the rates of change oscillate.

As the inflation rate applicable to a certain good rises, a consumer records this as, sensibly enough, inflation. As the rate declines, the consumer tends to discount it because the lower inflation rate is less salient, as noted above, and may be mentally accounted for as "good shopping." When price changes for a particular good are volatile, then not only is that good more likely to end up widely dispersed, but the very volatility itself will tend to create an impression of inflation.

This happens because the frame of reference for the price of a particular good will tend to be the previous price observed by a consumer, adjusted for an expected drift. Winer [1986], studying the implications for price-related sales promotion strategy of the way consumers form fair-price references, found considerable evidence supporting the notion that the relative price of an item compared with that seen at the prior purchase, adjusted for the drift trend, has a statistically significant effect on the brand-purchase decision. That is, "consumer brand choice decisions for two out of three major brands of coffee were strongly affected by discrepancies between expected and observed prices at the point of purchase" [Winer 1986, p.55]. For our purposes, predicting which brand a consumer will buy is unimportant. However, the author's further conclusion is relevant to us:

The important managerial implication of the results is that manufacturers may be penalized in the long run by frequent shortterm price-related deals since consumers make forecasting errors about the point-ofpurchase prices. An opposite strategy of infrequent price adjustments may allow price to become less important in the household brand choice process relative to advertising and product quality since observed prices at the point of purchase will be fully anticipated. [Winer 1986, p.55]

In other words, artificial point-of-purchase price volatility induced by marketing hurts manufacturer's long-run sales. Price volatility is a negative.

Tversky and Kahneman [1991, p. 1055], further citing both Winer [1986] and Kahneman, Knetsch, and Thaler [1986], imply that this effect operates due to repeated application of loss aversion phenomena, saying "asymmetric evaluations of gains and losses will affect the responses of both buyers and sellers to changes of price and profit, relative to the reference levels established in prior transactions." 15

Suppose that period-to-period percentage price changes are lognormally distributed with no drift. ${ }^{16}$ Then what we would like to do is to adjust inflation by the expected value of the "loss aversion" for a particular item category, given the category's standard deviation and the loss-aversion constant, $\lambda$.

If the distribution of percentage price changes is distributed as $N\left(\mu, \sigma^{2}\right)$-but we are abstracting from the trend price change $\mu$-then for random percentage changes drawn from this distribution

\footnotetext{
${ }^{15}$ But see also footnote 12 for an alternative hypothesis about the reference frame.

${ }^{16}$ This may or may not be true, and certainly is unlikely to be true for every surveyed price if only because of granularity effects and non-stochastic adjustment methodologies, but it seems a defensible approximation for our purposes. The nodrift assumption is clearly false - the regular price drift is called inflation-but as noted earlier consumers tend to take prior drift trends into account when ascertaining whether the price has changed relative to their expectations [Winer 1986].
} 
we want to know the expected value of the change, conditional on the change being positive, and the expected value of the change, conditional on the change being negative.

Adj $_{\text {Volatility }}$

$$
=\sum_{i} w_{i}\left\{\begin{array}{l}
E\left[N\left(0, \sigma_{i}^{2}\right)\right] \text { if } \triangle C P I_{i}<0, \\
E\left[N\left(0, \sigma_{i}^{2}\right)\right] / \lambda \text { if } \triangle C P I_{i} \geqslant 0 .
\end{array}\right.
$$

This reduces nicely. The first line of equation (4) expands, if we take $x=\Delta C P I_{i}$, to:

$$
\left\lfloor\int_{-\infty}^{0} x \frac{1}{2 \pi \sigma^{2}} e^{\frac{-x^{2}}{2 \sigma^{2}}} d x\right\rfloor / 0.5
$$

which evaluates to

$$
\frac{-\sigma \sqrt{2}}{\sqrt{\pi}} \approx-0.8 \sigma
$$

This is a well-known result describing the expected future value of a one-period, at-the-money put option (a put option's value, obviously, is defined as the absolute value of this quantity).

The call option, described in the second line of equation (4), is analogously priced at $0.8 \sigma$, but the value of this "option" is amplified by $1 / \lambda$ since upwards volatility is more keenly felt than downwards volatility. Accordingly, the adjustment for volatility is simply:

$$
A d j_{\text {Volatility }}=\sum_{i} w_{i}\left[\frac{0.8 \sigma_{i}}{\lambda}-0.8 \sigma_{i}\right],
$$

or simply

$$
\operatorname{Adj}_{\text {Volatility }}=0.8\left(\frac{1-\lambda}{\lambda}\right) \sum_{i} w_{i} \sigma_{i}
$$

It isn't a guarantee that the $\lambda$ in equation (5) is the same as the $\lambda$ in equation (3), but since both are coefficients of loss aversion, one would at least expect them to be closely related. In this exercise, they are taken to be the same scalar.

Figure 4 shows the result of applying equation (5) to the actual time series of CPI item strata. This adjustment is much more stable, because individual item volatilities change slowly over time. The large jumps in late 2001 and late 2008 are those associated with crisis levels of economic volatility.

\section{Other Biases}

Some other biases are worth discussion and further research but are difficult to quantify. I briefly discuss a few of them below.
Figure 4. Adj $j_{\text {volatility, }}$ 2000-2010

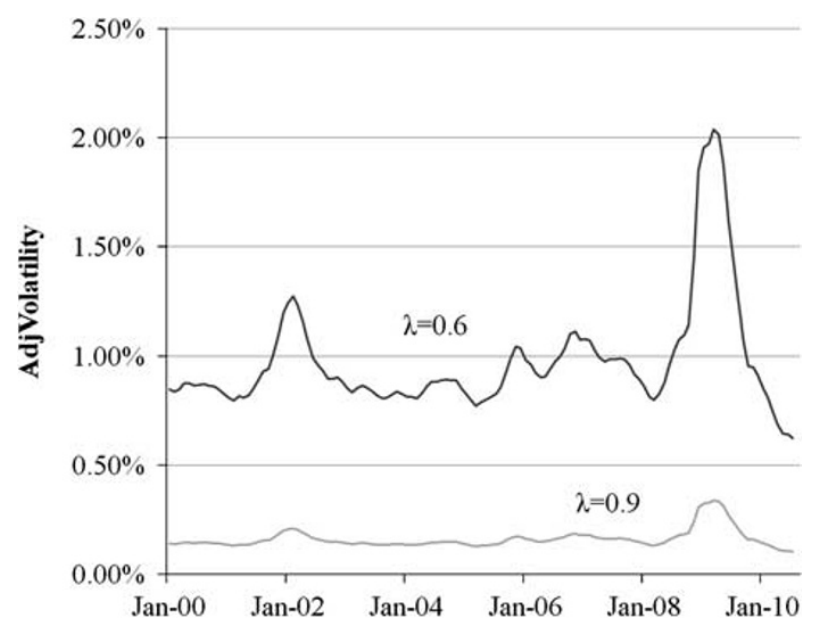

\section{Primacy/recency bias}

Psychologists recognize that people tend to have a better recollection, in a sequence of observations, of both the earliest observations and the later observations compared with the ones in the middle. These are called the "primacy" and "recency" effects, respectively. More interestingly, these observations are perceived to have more salience to the observer merely as a result of their temporal position.

This effect, I believe, is one reason that people tend to remember inflation when it involves the price of eggs (an item which has likely been purchased recently) more than they remember inflation in the price of cable television, even though the latter has roughly a dozen times the weight of the former in the average consumption basket.

Large purchases, even though infrequent, are made salient by their size. Accordingly, we might expect that consumers will tend to sense greater inflation when large and small items are inflating than when the median items (size-wise) are inflating. This hypothesis, however, must be subject to a future test, since the literature on quantifying the primacy/recency effects is decidedly thin.

\section{Failure to disentangle bundled costs}

Bundled costs, where some of the cost of an item represents current consumption and some represents investment or deferred consumption, are difficult to internalize correctly. This is unfortunate, because a very important part (about 25 percent) of the CPI involves the imputed cost for the consumption part of a capital good: owner-occupied housing. 
The goal of the CPI is to measure the cost of maintaining a given standard of living, and for that reason it is necessary to separate the cost of consuming housing from the value of a house as a financial asset. Prior to 1983, the cost of owneroccupied housing was recorded using the "asset price method." This method treated shelter costs as consisting of five elements: (1) home purchase, (2) mortgage interest costs, (3) property taxes, (4) homeowner insurance charges, and (5) maintenance and repair costs [Poole, Ptacek, and Verbrugge 2005, p. 11]. This is, viscerally, how homeowners tend to think about their cost of homeownership: principal plus interest plus taxes plus insurance plus maintenance.

Unfortunately, this is a cognitive error: homeowners are blending housing consumption costs with investment carry costs. This can be seen by noting that a homeowner can achieve essentially the same financial outcome by renting a house today and contracting to buy a different house, at a price fixed today but adjusted for inflation, in five years. Rental is clearly consumption; the contract to buy is clearly investment. The seller of the house will include in the forward price all the costs of carrying the house for five years: interest, taxes, insurance, maintenance, and the expected afterinflation change in the house's market price over that time.

The CPI, as a cost-of-living index, considers only the first part of that transaction, but the homeowner, of course, cares about both parts. When mortgage costs and taxes are rising, his standard of living is deteriorating; the fact that this is due to investment considerations and not consumption is a subtle point lost on him.

It is clear that this bias is upward (the consumer feels more inflation than is included in the CPI) when property taxes are rising, when mortgage rates are rising, and probably when real property values are rising (which causes new homeowners to take out larger mortgages and therefore pay more interest), and is biased lower when the opposite is true. But it is challenging to disentangle these effects, and I will leave it as a future improvement on the model.

Another case where entangled costs cause issues, also in shelter, is in the difference between "pure rent" and "economic rent." The BLS recognizes that rent paid to a landlord includes not only a payment for consumption of shelter but also in many cases a payment for ancillary services provided by the landlord. For example, the land- lord may not meter separately for utilities but some part of the tenant's rent in a "utilities included" rental represents the cost of those utilities. This means that when the cost of utilities rises while the rent stays the same, it means the implied cost of the housing itself declined. The renter, of course, is paying a constant rent and so will not realize that the true cost of his apartment has declined due to the rise in natural gas prices, and vice-versa. ${ }^{17}$ Accordingly, shelter costs will be mentally recorded as higher than the CPI reading when energy prices are rising and lower when energy prices are falling. This, too, is difficult to disentangle from the general effect of rising or falling energy prices.

\section{Internalizing tax increases as inflation}

The computation of the CPI excludes taxes that don't have anything to do with consumption, since CPI is only supposed to measure changes in the costs of consumption items. There is no question that rising (or, less commonly, declining) taxes affect our standard of living, but the question the CPI is meant to answer is not "what is the cost, in pre-tax dollars, of achieving the standard of living actually achieved in the base period." If income taxes are rising, it causes a decline in living standards that are achievable for someone receiving a given nominal wage; equivalently, that person will have to earn more money to purchase the same living standard. That sounds, and feels, like inflation to an ordinary person, but it is not.

In principle, this should be an easy adjustment to make. Total federal income taxes, divided by nominal GDP, gives the average tax burden as a percentage of income; using that ratio (we can refine it further with state and local levies, if desired) we can convert inflation into "effective pre-tax inflation rates."

The problem is that tax rates, and even the changes in tax rates, are not remotely close to evenly distributed. A large proportion of the citizenry pays effectively no taxes while a minority pays high rates. As a result, this particular effect is extremely heterogeneous. It is not even clear

\footnotetext{
${ }^{17}$ One reader of an earlier draft argued that since this practice artificially reduces the volatility of expenditure, it may tend to lower the sense of inflation. But in the context of the adjustments we are making, this is not the case, since volatility of prices produces an illusion of inflation. Removing the volatility removes the illusion induced by volatility, but does not actually induce a negative illusion. I am grateful for the opportunity to clarify that point.
} 
that we can get the direction of the effect correct, because total receipts may rise-implying that the general perception of inflation should be risingeven while the majority of consumers experience either a tax cut, or no change in taxes. Accordingly, I have not attempted to include this effect in the model.

There are doubtless other effects we can include, although many will be subject to debate. I believe the most important of the omissions to be some adjustment for the perception of housing costs relative to the recorded inflation in shelter consumption for owner-occupied housing, and I look forward to refinements of the model.

\section{Synthesis and Discussion}

The sum of the adjustments discussed above-including two widely discussed but economically unimportant ones and two rarely discussed but economically important ones-is:

$$
\begin{aligned}
& A d j_{S u b s}+A d j_{Q u a l}+A d j_{S e l M e m}+A d j_{\text {Volatility }} \\
& \quad=0.27 \%+0.1 \%+A d j_{\text {SelMem }}+A d j_{\text {Volatility }}
\end{aligned}
$$

The latter two terms of equation (6) are the results of equation (3) and equation (5), respectively. Both of those equations involve calculations based on readily available data but also rely on calibration of the $\lambda$ term.

There are at least two ways to determine what value of $\lambda$ is appropriate. The first is to take an existing survey measure and try to find what value of $\lambda$ is broadly consistent with the difference between the survey measure and the reported CPI.

Comparing the Michigan survey with the actual reported CPI (Figure 5), you can see an interesting phenomenon. The respondents to the Michigan survey sometimes see more inflation than is actually measured, but sometimes actually see less. Apart from the fact that this doesn't mesh at all with anecdotal evidence, the difference is small enough that it is easier to suspect it is merely noise. That is, the respondents to the Michigan survey are extremely efficient at assessing actual inflation, so that the actual difference between their responses and current inflation is merely chance.

From January 2000 to July 2010, the average absolute difference was 0.8 percent, but this was highly influenced by wide deviations around the time of the financial crisis. From January 2000 to September 2008, the average absolute difference between trailing one-year inflation and the Michigan survey's one-year (forward) inflation expectations
Figure 5. Michigan survey vs. reported CPI

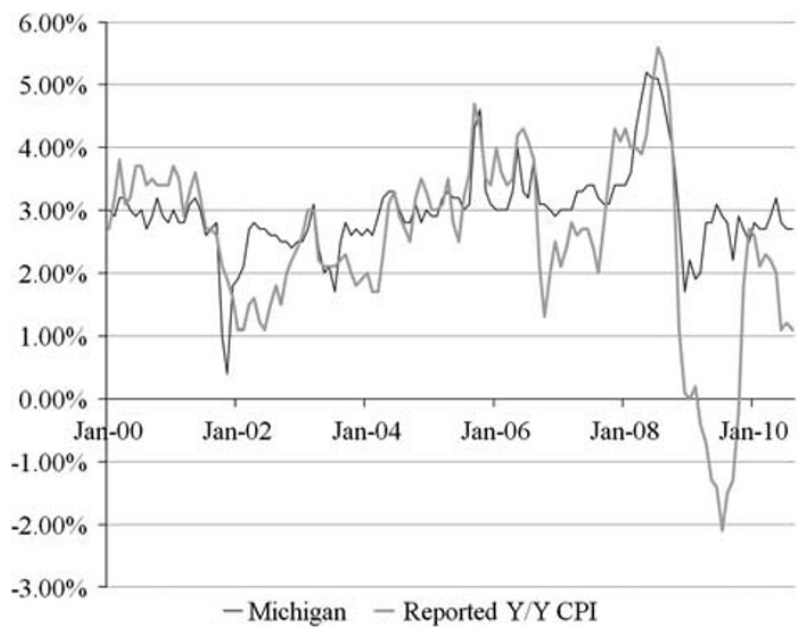

was only 0.5 percent. But more surprisingly, the average difference (retaining relative values) was only 0.1 percent over the shorter time period. This strongly suggests that respondents are either advanced econometric robots, or are in fact recalling what they have seen as the latest reported CPI figure and informing their responses with this information. Interestingly, Bryan and Venkatu [2001] found that in a study of multiple years of results from an inflation survey of Ohioans, respondents who said they had "heard of CPI" were able to quite accurately indicate by how much it had increased over the last year, and yet when asked about their own inflation experience responded on average that their experience of price increases ran 4 percent faster than the measured CPI (6.7 percent versus 2.7 percent over the survey period). Other studies have found similarly discouraging results about the perceptions of consumers: a 1986 survey in the United Kingdom [Bates and Gabor 1986] found that respondents overestimated the inflation of general grocery prices dramatically, at 16.8 percent per annum compared with an official rate of 4 percent! Given these results, it is hard to understand how the Michigan survey can be so close to reported CPI - either the Michigan respondents are simply lots more observant than the English and Ohioan respondents, or they are somehow anchoring on the CPI measure when they offer their responses.

Calibrating the model described in equation (6) to the Michigan survey results thus turns out to be impossible. The tracking error is so small that it implies essentially no loss aversion at all, which 
makes sense only if behavioral biases play no role in inflation perceptions.

In any event, calibrating a model to such a survey is not likely to be fully satisfactory for the same reasons, cited in the introduction and expanded on above, that the survey measure itself is unsatisfactory. Why calibrate a model to a survey measure that is not likely to accurately reflect what consumers really think is happening to prices?

The second approach is to experimentally evaluate consumer perceptions of inflation under test conditions designed to calibrate the behavioral effects discussed here. I have not attempted to do that, due to resource constraints, but I hope that other researchers will.

However, for illustrative purposes I have computed the aggregate upwards adjustment to headline inflation that would result from setting $\lambda=0.7$. The result of that exercise is shown in Figures 6 and 7.

There are several interesting implications of this analysis. One is that the aggregate adjustment seems to be slightly procyclical. The correlation between the level of headline inflation and the size of the aggregate adjustment, from 2000 to Jun-2008, is 0.14. But in the crisis, it became sharply anticyclical; the correlation run from Jul2008 to Aug-2010 is -0.62 and as a consequence the standard deviation of the "perceived" index was 18 percent lower than the standard deviation of the reported headline CPI over that time frame.

That is, during the financial crisis the large dispersion of price changes and the great volatility in prices generally served to blunt consumers' perception of the price declines, so that although

Figure 6. Aggregate adjustment for $\lambda=0.7$

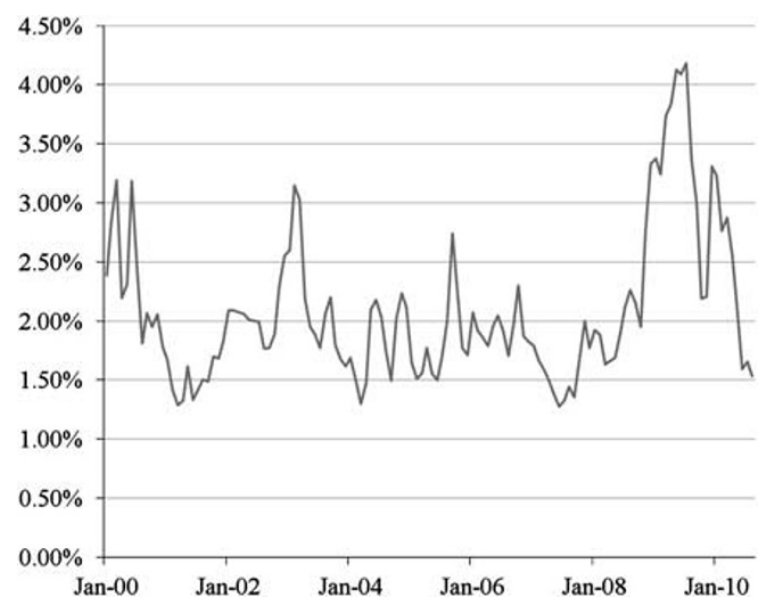

Figure 7. Perceived inflation vs. reported CPI

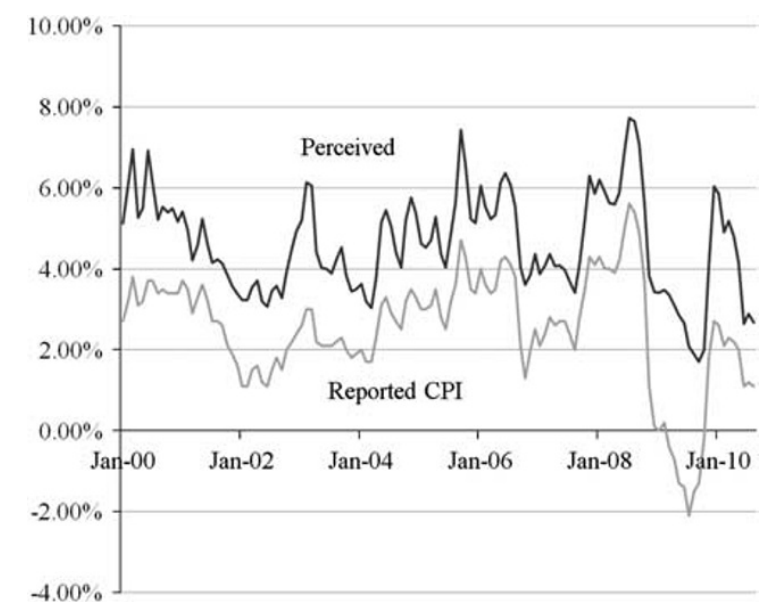

the country actually experienced deflation, consumers didn't perceive it as such. There are of course competing explanations for the fact that the sharp compression in activity did not affect inflation as dramatically as some expected, but this analysis suggests (and quantifies!) a behavioral reason that may also have been in play.

\section{Conclusion}

It may seem strange, to purists, that I am arguing in favor a model that is clearly mis-measuring the underlying phenomenon of price inflation. Indeed, I think we can state unequivocally that those who claim that the inflation rate as reported is substantially understating the true rate of inflation are simply wrong. One particular, somewhat popular website claims that CPI understates actual inflation by some 7 percent per annum. This is absurd, and rudimentary arithmetic illustrates the absurdity:

Using government statistics (specifically, the Employment Cost Index), we can figure that someone earning \$20,000 in after-tax wages in 1980 should be now making roughly $\$ 59,300 .{ }^{18}$ The original $\$ 20,000$ standard of living now should cost, according to CPI, some $\$ 52,800$, so this person is somewhat better-off. However, if we use a 7 percent higher rate of inflation, the $\$ 20,000$ standard-of-living in 1980 now should cost $\$ 353,000$. I would hope that consumers generally

\footnotetext{
${ }^{18}$ This assumes, improbably, that taxes were unchanged but we will see this imprecision is small enough to be irrelevant for the illustration.
} 
would notice a seven-fold decline in their living standards. ${ }^{19}$

I don't intend for the methodology cited in this paper to be used to support the conspiracy mythology that the government is trying to "stick it to us" by falsifying CPI. So I want to say very clearly that even as we seek to measure consumer perceptions of inflation, we should recognize that consumers are wrong. Inflation is certainly not as high as they think it is.

That doesn't mean, however, that this is a pointless exercise. After all, while no one would argue that the thermometer is falsifying the actual temperature, we nevertheless calculate "wind chill" or "real feel" temperatures to express a sense of how the temperature outside will feel on exposed skin. Even though this number is "wrong" in the sense that it doesn't measure the true temperature, it is more predictive of the risks of exposure. Thus, it matters more to people who may be venturing out-of-doors.

In the case of inflation, although consumers are wrong about the actual pace of changes in prices, their perceptions matter. Their perceptions of inflation will affect their perceptions of real yields and, therefore, investment opportunities. ${ }^{20}$ Their perceptions may also feed more efficiently into price pressures via a cost-push inflation mechanism. For example, workers who perceive a higher inflation rate may hold out for higher wage increases. If true, this will matter to policymakers.

The existence of such biases helps to explain several puzzles in the literature. For example, Bryan and Venkatu [2001] found in their survey of Ohioan inflation expectations that even after adjusting for income, marital status, ethnic and age group affiliations, and market basket, women still had higher inflation perceptions than did men. One possible explanation is that since women (still) tend to do more of the household's shopping

\footnotetext{
${ }^{19}$ Assuming a 7 percent higher rate of inflation would also mean that housing over the last decade not only wasn't in a bubble, it didn't even come close to keeping up with inflation. Nor did any other asset. That's worse than nonsense.

${ }^{20}$ We might even speculate that this could be one reason centrally planned economies have difficulty with growth; by eliminating price variability and dispersion, they artificially lower the perceived inflation rate closer to the actual inflation rate and thereby increase the perceived real interest rate. Or, contrariwise, in open economies with mis-perceived inflation, investment may be made on the basis of a lower perceived cost of capital.
}

than do men, these cognitive biases have more opportunities to affect their perceptions.

Mankiw, Reis, and Wolfers [2003] found that disagreement among survey respondents about the future path of inflation tends to (a) rise with inflation, (b) rise when inflation changes sharply, (c) rise in concert with dispersion in rates of inflation across commodity groups, and (d) show no clear relationship with measures of real activity. The model developed in this paper clearly explains (b) and (c), and confirms - at least, in noncrisis periods - that (a) should be expected.

It makes sense to pursue research along the lines of inquiry that have been laid out here for the value such research can have in illuminating such findings. This model and discussion can be viewed as a starting point on the path. The implications for our understanding of how consumers interact in the economy to produce real outcomes are significant. But also, of course, it is important for policymakers looking at inflation perceptions as an anchoring influence to understand that there may be such an influence, but the anchor isn't necessarily set where they think it is.

\section{Acknowledgments}

The author would like to thank Luca Vidozzi, Robert McClelland, John Huston, Thomas Jacobs, Henry Willmore, Marty McGuire, and two anonymous referees for their comments on earlier drafts of this paper.

\section{REFERENCES}

Akerloff, G.A., and R.J. Shiller. 2009. Animal Spirits: How Human Psychology Drives the Economy, and Why It Matters for Global Capitalism. Princeton University Press.

Ashton, M. 2008. "Inflation-Linked Corporate Bond Spreads-Are Corporate Linkers Really As Rich As They Look?" Euromoney Derivatives \& Risk Management Handbook 2008/09, 27-36.

Bates, J., and A. Gabor. 1986. "Price Perception in Creeping Inflation: Report on an Enquiry." Journal of Economic Psychology, 7: 291-14.

Bernanke, B.S. 2007. "Inflation Expectations and Inflation Forecasting," At the Monetary Economics Workshop of the National Bureau of Economic Research Summer Institute, Cambridge, MA, July 10, http://www.federal reserve.gov/newsevents/speech/bernanke20070710a.htm.

Board of Governors of the Federal Reserve System, 2006. "Press Release," September 20, http://www.federal reserve.gov/newsevents/press/monetary/20060920a.htm. 
Board of Governors of the Federal Reserve System, 2008. "Press Release," 2008, August 5, http://www.federal reserve.gov/newsevents/press/monetary/20080805a.htm.

Board of Governors of the Federal Reserve System, 2010. "Press Release," June 23, http://www.federalreserve .gov/newsevents/press/monetary/20100623a.htm.

Bryan, M.F., and G. Venkatu. 2001. The Curiously Different Inflation Perspectives of Men and Women. Federal Reserve Bank of Cleveland.

Canetti, E.R., D.E. Lebow, J.B. Rudd, and A. Blinder. 1998. Asking About Prices: A New Approach to Understanding Price Stickiness. Russell Sage Foundation Publications.

Darin, R., and Robert L. Hetzel. 1995. "An Empirical Measure of the Real Rate of Interest." Federal Reserve Bank of Richmond, Economic Quarterly, 81(Winter): 17-47.

Fischer, C.C. 1986. "The Differential Impact of Inflation on Key Societal Interest Groups and Public Policy Implications." Journal of Economic Psychology, 7: 371-86.

Gordon, R. 2004. "Apparel Prices 1914-1993 and the Hulten/Bruegel Paradox," presented at the CRIW Conference on Price Index Concepts and Measurement, Vancouver, http://faculty-web.at.northwestern.edu/ economics/gordon/Apparel1.pdf.

Gordon, R., and T. VanGoethem. 2005. "A Century of Housing Shelter Prices: Is There a Downward Bias in the CPI?," NBER Working Paper \#11776. www.nber .org/papers/w11776.pdf.

Greenlees, J.S., and R.B. McClelland. 2008. "Addressing misconceptions about the Consumer Price Index." Monthly Labor Review 131(8): 3-19.

Gürkaynak, R.S., B. Sack, and E. Swanson. 2005. "The Sensitivity of Long-Term Interest Rates to Economic News: Evidence and Implications for Macroeconomic Models." American Economic Review, 95(1): 425-36.

Johnson, D.S., S.B. Reed, and K.J. Stewart. 2006. "Price Measurement in the United States: a Decade Aftert he Boskin Report." Monthly Labor Review 129(5): 10-19.

Kahneman, D., and A. Tversky. 1979. "Prospect Theory: An Analysis of Decision under Risk." Econometrica, 47: 263-91.
Kahneman, D., J.L. Knetsch, and R. Thaler. 1986. "Fairness as a Constraint on Profit Seeking: Entitlements in the Market." The American Economic Review, 76: $728-41$.

Leonhardt, D. 2008. "Seeing Inflation Only in the Prices That Go Up," New York Times (May 7), http://www .nytimes.com/2008/05/07/business/07leonhardt.html.

Levin, A., F. Natalucci, and J. Piger. 2004. "The Macroeconomic Effects of Inflation Targeting." Federal Reserve Bank of St. Louis. Review, 86(July): 51-80.

Mankiw, N.G., R. Reis, and J. Wolfers. 2003. "Disagreement about Inflation Expectations," NBER Working Paper No. W9796. Available at SSRN: http:// ssrn.com/abstract $=418298$.

Mishkin, F.S. 2007. "Inflation Dynamics." International Finance, 10(3): 317-34.

Poole, R., F. Ptacek, and R. Verbrugge. 2005. Treatment of Owner-Occupied Housing in the CPI. Office of Prices and Living Conditions, U.S. Bureau of Labor Statistics.

Ranyard, R., F. Del Missier, N. Bonini, D. Duxbury, and B. Summers. 2008. "Perceptions and Expectations of Price Changes and Inflation: a Review and Conceptual Framework." Journal of Economic Psychology, 29: 378-400.

Spencer, R.W., and J.H. Huston. 1993. "Rational Forecasts: on Confirming Ambiguity as the Mother of Conformity." Journal of Economic Psychology, 14(4): 697-709.

Taylor, J.B. 1993. "Discretion versus Policy Rules in Practice." Carnegie-Rochester Conference Series on Public Policy 39(1): 195-14.

Tversky, A., and D. Kahneman. 1974. "Judgement Under Uncertainty: Heuristics and Biases." Science, 185(4157): 1124-31.

Tversky, A., and D. Kahneman. 1991. "Loss Aversion in Riskless Choice: A Reference-Dependent Model." The Quarterly Journal of Economics, 106(4): 1039-61.

U.S. Bureau of Labor Statistics, 2010. "CPI FAQ: Question \#4," Retrieved July 9, 2010, from http://www .bls.gov/cpi/cpifaq.htm\#Question_4.

Winer, R.S. 1986. "A Reference Price Model of Brand Choice for Frequently-Purchased Products." Journal of Consumer Research, 13: 250-6. 